\title{
Images in Anesthesia: Airway obstruction after peanut aspiration - air trapping is due to airway distension and narrowing
}

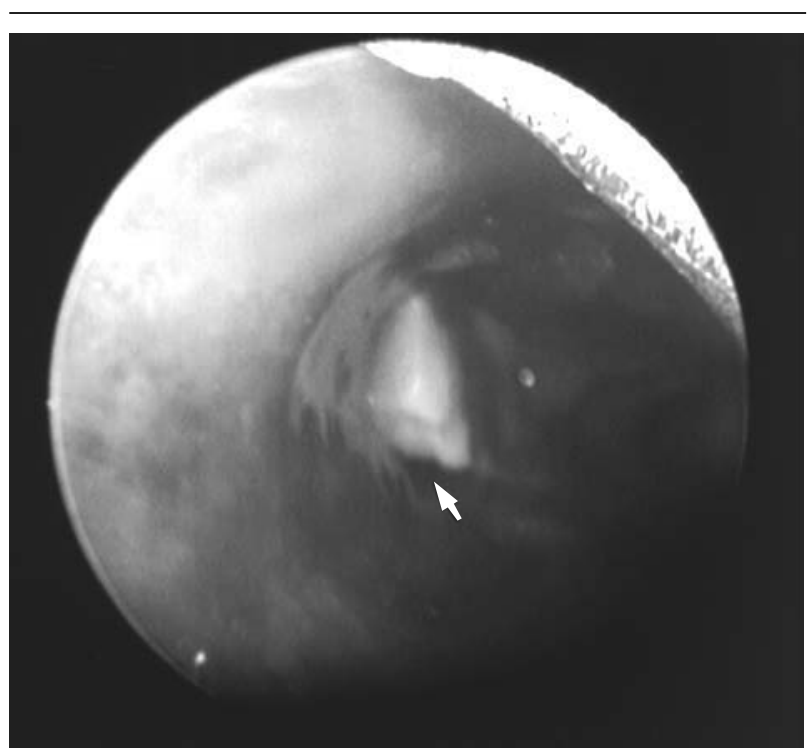

FIGURE 1A Rigid bronchoscopic view of carina and aspirated peanut; a slight opening (arrow) in the left mainstem bronchus during spontaneous inhalation is evident.

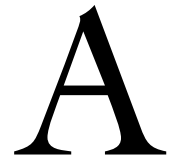

24-month-old boy presented with increasing cough and mild fever $15 \mathrm{hr}$ after choking and transiently turning cyanotic while eating peanuts. Chest auscultation revealed decreased air entry, and the chest $x$-ray showed hyperinflation on the left.

The patient underwent rigid bronchoscopy under general anesthesia. Spontaneous respiration (with gentle assistance) with $100 \%$ oxygen was maintained. After lidocaine topicalization of the larynx and trachea, a bronchoscopy revealed a peanut in the left mainstem bronchus. On real time video, the peanut was seen immobilized. Dilatation and contraction of the bronchial lumen with inspiration and expiration, respectively, led to air trapping. The peanut was not bobbing up and down like a ball, as the term "ballvalve" effect may suggest (Figure $1 \mathrm{~A}$ and $1 \mathrm{~B}$ ). Figure 2 shows partial obstruction of the tracheal lumen after the peanut was dropped accidentally by the retrieving forceps. Again, one witnesses the role of airway distention and narrowing during respiration as the mechanism of air trapping in intrathoracic airway obstruction.

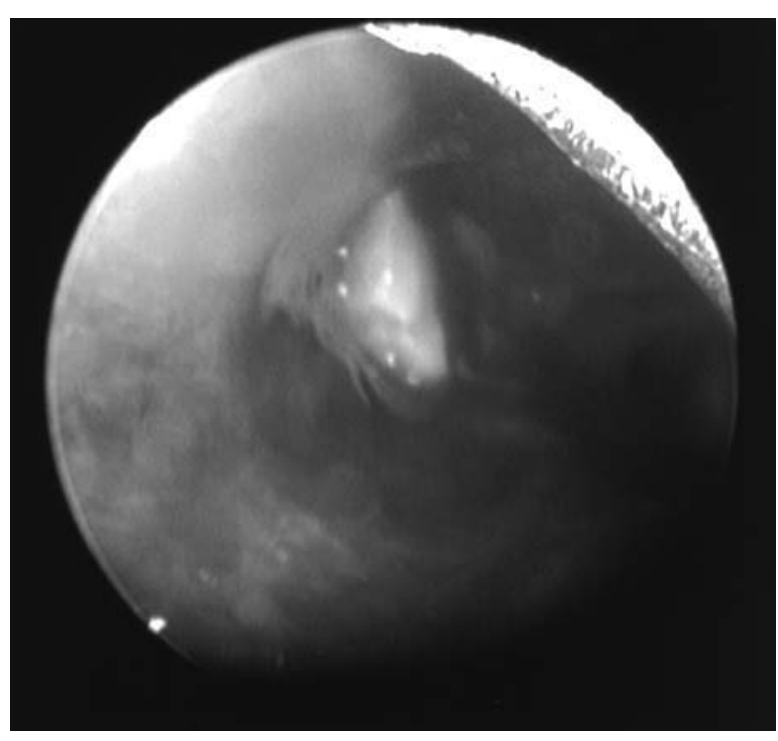

FIGURE 1B Slight opening in the left mainstem bronchus is no longer visible during spontaneous exhalation because of narrowing of the bronchial lumen.

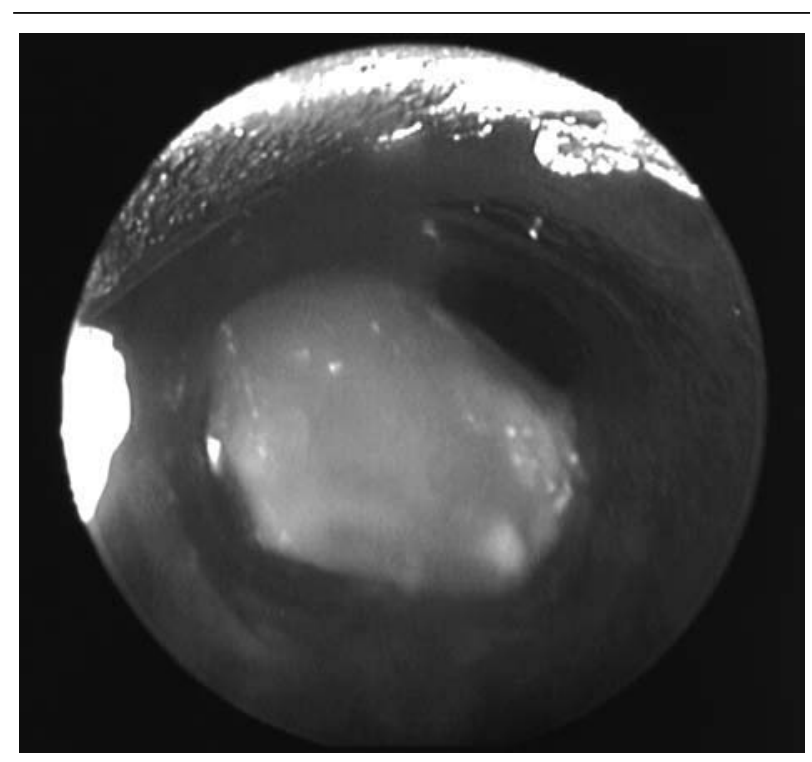

FIGURE 2 The peanut was dropped accidentally from forceps during retrieval but did not immediately lead to complete obstruction because the tracheal lumen is larger than the mainstem bronchial lumens. 
Foreign body aspiration is a common emergency and causes 300 deaths per year in the US, with one to two-year-olds being the most affected. ${ }^{1,2}$ A peanut causes inflammation of the airway, exacerbating the obstruction. The mechanism explaining air trapping appears to be related mainly to airway distension and narrowing during respiration.

Anthony M.-H. Ho MSC MD FRCPC FCCP

Gordon SOo MBBS FRCS

Sumin Lee MBBS

David C. Chung MD FRCA FRCPC

Lester A. H. Critchley MD FRCA

Manoj K. Karmakar MD FRCA

Hong Kong, China

\section{References}

1 Roberts JR, Benjamin JT, Fox S. Crunchy peanut butter: a cause of foreign body aspiration in children. Clin Pediatr 1996; 35: 591-2.

2 Cataneo AJ, Reibscheid SM, Ruiz Junior RL, Ferrari $G F$. Foreign body in the tracheobronchial tree. Clin Pediatr 1997; 36: 701-6. 